\title{
In Vivo Composition of NMDA Receptor Signaling Complexes Differs between Membrane Subdomains and Is Modulated by PSD-95 And PSD-93
}

\author{
Ilse Delint-Ramirez, ${ }^{1,2}$ Esperanza Fernández, ${ }^{1}$ Alex Bayés, ${ }^{1}$ Emese Kicsi, ${ }^{3}$ Noboru H. Komiyama, ${ }^{1}$ and Seth G. N. Grant ${ }^{1}$ \\ ${ }^{1}$ Genes to Cognition Programme, Wellcome Trust Sanger Institute, Genome Campus, Hinxton, Cambridgeshire CB10 1SA, United Kingdom, ${ }^{2}$ Departamento \\ de Neurociencias, Instituto de Fisiología Celular, Universidad Nacional Autónoma de México, A.P. 70-253 México D.F., 04510, México, and ${ }^{3}$ Department of \\ Neuroscience, Edinburgh University, Edinburgh EH8, United Kingdom
}

Lipid rafts are dynamic membrane microdomains enriched in cholesterol and sphingolipids involved in the compartmentalization of signaling pathways, trafficking and sorting of proteins. At synapses, the glutamatergic NMDA receptor and its cytoplasmic scaffold protein PSD-95 move between postsynaptic density (PSD) and rafts following learning or ischemia. However it is not known whether the signaling complexes formed by these proteins are different in rafts nor the molecular mechanisms that govern their localization. To examine these issues in vivo we used mice carrying genetically encoded tags for purification of protein complexes and specific mutations in NMDA receptors, PSD-95 and other postsynaptic scaffold proteins. Isolation of PSD-95 complexes from mice carrying tandem affinity purification tags showed differential composition in lipid rafts, postsynaptic density and detergent-soluble fractions. Raft PSD-95 complexes showed less CaMKII $\alpha$ and SynGAP and enrichment in Src and Arc/Arg3.1 compared with PSD complexes. Mice carrying knockouts of PSD-95 or PSD-93 show a key role for PSD-95 in localizing NR2A-containing NMDA receptor complexes to rafts. Deletion of the NR2A C terminus or the C-terminal valine residue of NR2B, which prevents all PDZ interactions, reduced the NR1 association with rafts. Interestingly, the deletion of the NR2B valine residue increased the total amount of lipid rafts. These data show critical roles for scaffold proteins and their interactions with NMDA receptor subunits in organizing the differential expression in rafts and postsynaptic densities of synaptic signaling complexes.

\section{Introduction}

Biological membranes are composed of different subdomains that compartmentalize the spatial distribution of receptors and membrane-proximal effectors. Lipid rafts are small (10-200 $\mathrm{nm}$ ), heterogeneous, highly dynamic, sterol- and sphingolipidenriched membrane domains. Lipid rafts enriched in saturated fatty acids are dispersed in the more fluid liquid-disordered phase of more unsaturated lipids (Pike, 2006). Signaling proteins with affinity for rafts become concentrated in these microdomains, thus facilitating formation of protein complexes and activation of specific signaling pathways (Simons et al., 1998).

Single-quantum dot imaging of glycophosphatidyl-inositol anchored green fluorescent protein in mammalian synapses found postsynaptic membranes had lipid-raft properties (Renner et al., 2009). Several studies showed rafts and PSDs share important signaling proteins including neurotransmitter receptors

\footnotetext{
Received April 8, 2010; accepted May 1, 2010.

This work was supported by scholarship from Consejo Nacional de Ciencia y Tecnologia (México) and Coordinación de la Investigación Científica, Universidad Nacional Autónoma de México to I.D.-R. A.B. was supported by the European Molecular Biology Organization and the European Commission. E.F., E.K., N.H.K., and S.G.N.G. were supported by the Wellcome Trust. PSD-93 mice were provided by D. Bredt; NR2A ${ }^{\Delta C / \Delta C}$ was provided by P. Seeburg and R. Sprengel. We thank D. Fricker and K. Elsegood for genotyping and colony management.

Correspondence should be addressed to Dr. Seth G.N. Grant, Wellcome Trust Sanger Institute, Genome Campus, Hinxton, Cambridgeshire, CB10 1SA, UK. E-mail: sg3@sanger.ac.uk.

DOI:10.1523/JNEUROSCI.1792-10.2010

Copyright $\odot 2010$ the authors $\quad 0270-6474 / 10 / 308162-09 \$ 15.00 / 0$
}

such as NMDA receptors (NMDAR), the scaffolding protein PSD-95 and downstream kinases (Becher et al., 2001; Suzuki et al., 2001; Ma et al., 2003; Guirland et al., 2004; Besshoh et al., 2005). Moreover, movement of NMDAR from lipid rafts to PSDs was reported following ischemia and this was correlated with increased tyrosine phosphorylation of NR2A and NR2B subunits in rafts (Besshoh et al., 2005). The shift of NMDAR and PSD-95 between PSD and rafts also occurs with spatial learning induced in the water maze (Delint-Ramírez et al., 2008). These data suggests the possibility that signaling complexes formed by NMDAR and PSD-95 may have different signaling functions in rafts.

PSD-95 is a palmitoylated protein of the membrane associated guanylate kinase family (MAGUK) (Melkonian et al., 1999; Zacharias et al., 2002) and promotes the association of others proteins with lipid rafts (Ma et al., 2003; Wong and Schlichter, 2004). The C-terminal ESDV motifs of NR2A and NR2B directly interact with the PDZ domains of MAGUKs (Kornau et al., 1995; Sheng, 2001) to form multiprotein complexes known as the NMDAR complex/MAGUK associated signaling complex (NRC/ MASC) (Husi et al., 2000; Husi and Grant, 2001; Collins et al., 2006; Emes et al., 2008). Proteomic studies of NRC/MASC has identified scaffold proteins, kinases, phosphatases, GTPaseactivating proteins and effectors which are key components of diverse signal transduction pathways (Husi et al., 2000; Husi and Grant, 2001; Collins et al., 2005, 2006; Coba et al., 2009). A powerful new method for isolating mouse protein complexes, where 
endogenous PSD-95 is genetically modified to encode a Tandem Affinity Purification (TAP) tag, shows 118 proteins comprising key electrophysiological machinery of the postsynaptic excitatory synapse (Fernández et al., 2009). These genetically modified mice, known as PSD-95 ${ }^{\mathrm{TAP}}$ mice, have broad application in the study of synapse complexes.

Here we use PSD-95 ${ }^{\text {TAP }}$ mice to study the composition of PSD-95 complexes in lipid rafts. Using mice carrying knock-outs in MAGUK proteins, deletions of specific domains and point mutations of NMDAR subunits we identify the role of specific protein interactions promoting the association of signaling complexes with rafts.

\section{Materials and Methods}

Genetically modified mice. Animals were treated in accordance with UK Animal Scientific Procedures Act (1986) and NIH guidelines. All the experiments were performed using wild-type and homozygous littermates matched animals.

$P S D-95^{T A P}$ mice were knock-in mice in which a Tandem Affinity $\mathrm{Pu}-$ rification (TAP) tag was inserted into the endogenous locus of PSD-95 (Fernández et al., 2009). The TAP tag consists of a poly-histidine affinity tag (HAT) and a triple FLAG tag (Terpe, 2003) separated by a unique TEV-protease cleavage site (Fernández et al., 2009).

$P S D-93^{-1-}$ knock-out mice do not express detectable levels of the protein PSD-93 (McGee et al., 2001).

PSD-95 ${ }^{-1-}$ knock-out mice do not express detectable levels of the protein PSD-95 (Yao et al., 2004).

$N R 2 A^{\Delta C / \Delta C}$ mice that express NR2A subunit lacking the intracellular $\mathrm{C}$-terminal domain were constructed by deleting the C-terminal exon of the NR2A subunit gene (Sprengel et al., 1998).

$N R 2 B^{\Delta V / \Delta V}$ mice express the NR2B subunit carrying a deletion of the C-terminal Valine 1482. A detailed description of the generation of these mutant mice is in preparation (N. H. Komiyama, E. Kicsi, S. G. N. Grant, unpublished).

Antibodies. Mouse anti-NR1 (catalog \#320500 Zymed), rabbit antiNR2A (catalog \#OPA1-04021, Affinity BioReagents-Thermo Fisher Scientific), rabbit anti-NR2A (catalog \#07-632, Millipore), rabbit antiNR2A (N-terminal) (catalog \#AHP1880 ABD-Serotec, MorphoSys) mouse anti-NR2B (catalog \#610416/7, BD Biosciences), mouse antiPSD-95 (catalog \#MA1-045, Affinity BioReagents-Thermo Fisher Scientific), mouse anti-PSD-93 (catalog \#75-057, NeuroMab), mouse anti-PSD-93 (catalog \#75-058 NeuroMab), rabbit anti-SRC (catalog \#ab7950 Abcam), mouse anti-actin (catalog \#ab3280, Abcam) rabbit anti-Flotilli-1 (catalog \#F1180, Sigma-Aldrich), mouse anti-Arc (Santa Cruz Biotechnology), rabbit anti-SynGAP (catalog \#PA1-046 Affinity BioReagents-Thermo Fisher Scientific), rabbit anti-1252 PY-NR2B (catalog \#ab18532, Abcam).

Isolation of lipid rafts. Lipid rafts were prepared from insoluble extract of homogenate tissue as described previously (Marta et al., 2003) with some modifications (Delint-Ramírez et al., 2008). Mouse cortex was homogenized in lysis buffer $(0.5 \mathrm{ml}$ of $150 \mathrm{~mm} \mathrm{NaCl}, 25 \mathrm{~mm}$ Tris- $\mathrm{HCl}$, $\mathrm{pH} 7.5$, containing $50 \mathrm{~mm} \mathrm{NaF}, 10 \mathrm{mM} \mathrm{NaP}_{2} \mathrm{O}_{7}, 1$ mM sodium orthovanadate, Complete protease inhibitor cocktail (Roche) and 1\% Triton $\mathrm{X}-100)$. Following homogenization (30 strokes) with a Teflon glass homogenizer the sample was centrifuged $10 \mathrm{~min}$ at $1500 \times g$ and protein concentration determined by Bradford assay. The supernatant ( 3 or 3.5 $\mathrm{mg}$ of protein) was incubated for $30 \mathrm{~min}$ at $4^{\circ} \mathrm{C}$ and centrifuged $15 \mathrm{~min}$ at $16,000 \times g$ at $4^{\circ} \mathrm{C}$, to separate a Triton X-100 soluble extract and the insoluble pellet. The pellet was resuspended in $0.5 \mathrm{ml}$ of lysis buffer and mixed with $2 \mathrm{M}$ sucrose $(1 \mathrm{ml})$, overlaid with $1 \mathrm{M}(2 \mathrm{ml})$ and $0.2 \mathrm{M}(1.5 \mathrm{ml})$ sucrose and centrifuged for $18 \mathrm{~h}$ at 200,000 $\times g($ SW $50 \mathrm{Ti}$; Beckman $)$ at $4^{\circ} \mathrm{C}$. After centrifugation, five $1 \mathrm{ml}$ fractions were collected at $4^{\circ} \mathrm{C}$ from the top (fraction 1) to the bottom of the gradient. The pellet was resuspended in $1 \mathrm{ml}$ of lysis buffer. Protein concentration was measured by Bradford assay. Equal volumes of each gradient fraction were measured for the lipid rafts markers GM1, cholesterol, Src and flotillin-1. The highest concentration of all these proteins was found in fraction 2 (Fig. 1) as previously reported. The pellet is a high-density insoluble fraction that contains the major proportion of postsynaptic density proteins (PSD-93, PSD-95, GLUR1, NMDAR). The pellet did not show any detectable levels of lipids such as cholesterol or GM1 (Fig. 1), thus we considered this fraction contains the PSDs depleted of lipid rafts (Fig. 1). Therefore, fraction 2 is referred to as the lipid raft fraction and the pellet as PSD fraction.

Isolation of PSD-95 complexes. Lipid rafts and PSD fractions were isolated from PSD-95 ${ }^{\mathrm{TAP}}$ mice. Lipid raft fractions $(1 \mathrm{ml})$ were diluted with $4 \mathrm{ml}$ of $150 \mathrm{~mm} \mathrm{NaCl}, 25 \mathrm{~mm}$ Tris- $\mathrm{HCl} \mathrm{pH} \mathrm{7.5,} \mathrm{containing} \mathrm{Complete}$ protease inhibitor cocktail (Roche) and centrifuged for $35 \mathrm{~min}$ at 45,000 rpm. (SW $50 \mathrm{Ti}$; Beckman) at $4^{\circ} \mathrm{C}$. The lipid raft pellet and the PSD fraction were resuspended by sonication in $0.3 \mathrm{ml}$ of lysis buffer plus $0.2 \%$ sodium deoxycholate. Both extracts were centrifuged for $15 \mathrm{~min}$ at $16,000 \times g$ at $4^{\circ} \mathrm{C}$ and the supernatants were incubated with anti-FLAG antibody covalently coupled to Dynal beads (Invitrogen). After $2 \mathrm{~h}$ of mixing at $4^{\circ} \mathrm{C}$, the beads were washed three times with $0.4 \mathrm{ml}$ of lysis buffer and once with $0.4 \mathrm{ml}$ of $150 \mathrm{~mm} \mathrm{NaCl}, 25 \mathrm{~mm}$ Tris-HCl, pH 7.5. The tagged protein was cleaved from the beads by addition of TEV protease as previously described (Fernández et al., 2009).

Immunoblot analysis. Equal volumes of each fraction or $2 \mu \mathrm{g}$ of protein from lipid rafts and PSD fractions, $120 \mu \mathrm{g}$ from detergent-soluble extract and $20 \mu \mathrm{g}$ from homogenized mice cortex were mixed with NuPAGE LDS Sample Buffer plus $5 \% \beta$-mercaptoethanol, boiled and separated in $4-12 \%$ LDS Bis-Tris Gels (NuPAGE, Invitrogen). Proteins were electrophoretically transferred to PVDF membrane at $40 \mathrm{~V}$ overnight. The membrane was then blocked for $2 \mathrm{~h}$ at room temperature in TBS-T buffer (Tris $10 \mathrm{~mm}, \mathrm{NaCl}$ 0.9\%, Tween 20 0.1\%, pH 7.5) containing 5\% BSA. Membranes were incubated with primary antibodies for $24 \mathrm{~h}$ at $4^{\circ} \mathrm{C}$, washed (4 times $/ 5 \mathrm{~min}$ ) in TBS-T, and incubated for $1 \mathrm{~h}$ with HRPconjugated secondary antibody. Negative controls were prepared by omission of primary antibodies. Proteins were detected by ECL (Immobilon Wester, Millipore) and visualized by Kodak Image Station. Levels of immunoreactivity were quantified densitometrically with the ImageJ $1.31 \mathrm{~V}$ software (Wayne Rasband, National Institutes of Health, Bethesda, MD).

Determination of lipid amount. To determine the level of monosialoganglioside (GM1), $1 \mu$ l of each density gradient fraction were dot blotted onto nitrocellulose, and blocked as described above. After incubation with HRP-conjugated cholera toxin B (1/10.000) (Sigma), the dots were revealed by chemiluminescence as above. Cholesterol concentration was determined colorimetrically by enzymatic method using Total Cholesterol Test kit (Wako Pure Chemical). Equal volumes of the fractions of the gradients were analyzed.

Statistical analysis. Statistical differences between samples were evaluated using the unpaired Student's $t$ test. We use a minimum of 5 litter matched pairs of animals, except detergent-soluble extract (4 litter matched pair of animals). All results are expressed as the mean \pm SEM.

\section{Results}

\section{NMDAR-PSD-95 complexes isolated from lipid rafts}

Figure $1 A$ shows fractionation of mouse cortex extracts into lipid rafts (fraction 2), PSDs (pellet) and other fractions (see Materials and Methods) from wild-type and PSD-95 ${ }^{\text {TAP }}$ mice. Equal amounts of protein from the lipid rafts and PSD fractions were then subject to affinity purification of PSD-95-NMDAR complexes followed by immunoblotting for NMDA receptor subunits, MAGUKs and other associated proteins (Fig. 1B). No proteins were detected in wild-type mice revealing the specificity of the TAP method (Fig. $1 B$ ).

Differential composition of PSD-95 complexes was observed between rafts and PSD (Fig. 1B). PSD-95 complexes isolated from lipid rafts had similar proportions of NR1 and NR2A subunits compared with those isolated from the PSD fraction $(p>$ $0.05)$. However, several proteins were reduced in lipid rafts when compared with PSDs: NR2B $(p<0.01)$, SynGAP $(p<0.01)$ and CaMKII $\alpha(p<0.01)$. In contrast to the reduction in these three proteins, very significant increases in the proportions of 
Arc/Arg3.1 $(p<0.01)$ and $\operatorname{Src}(p<0.01)$ were observed in rafts. Since Src is known to phosphorylate NR2B on Y1252, we examined the phosphorylation of this site and found a higher phosphorylation of NR2B pY1252 in the lipid raft fraction, indicating the functional significance of the differential composition of the PSD-95 complexes in rafts. In addition to NR1 and NR2A we did not find significant differences in PSD-93 $(p>0.05)$ and SAP-102 ( $p=0.08)$ levels among both fractions (Fig. $1 B$ ).

We next examined the detergentsoluble extract, which does not include rafts or PSD (see Materials and Methods) to ask whether this fraction also showed differential composition of PSD-95 ${ }^{\text {TAP }}$ complexes. As shown in Figure $1 C$, the soluble extract used for the affinity purification contains NR1, NR2B, PSD-95, Arc/ Arg3.1 and CaMKII $\alpha$, however these proteins were not assembled into complexes with PSD-95 (the soluble extract contains a total protein concentration $\sim 60$ times higher than the raft and PSD fractions) (Fig. 1D). Together these data show that complexes formed by PSD-95, NMDA receptor and their associated signaling proteins have differential composition in rafts, PSD and soluble fractions.

\section{Differential roles for PSD-95 and} PSD-93 in NMDAR association with lipid rafts

To test whether MAGUK proteins influence the association of NMDA receptors (NMDAR) with rafts, we examined the distribution of NMDAR subunits in rafts, PSD and detergent-soluble fractions from mice lacking PSD-95 or PSD-93. We first examined PSD-95 knock-out mice (PSD$95^{-1-}$ ) and confirmed that the total amount of cortical rafts was similar in wt and $P S D-95^{-1-}$ mice, as reflected by the unchanged levels of lipid rafts markers (GM1 and flotillin) (Fig. 2A). Then, we analyzed equal protein amounts of lipid rafts and PSDs by Western blot for NMDAR subunits, MAGUKs (PSD-95 and PSD-93) and flotillin-1 or actin. Surprisingly, NR1 and NR2A concentrations in lipid rafts were higher in $P S D-95^{-1-}$ mice (Fig. $2 A$ ), while NR2B remained constant. Importantly, none of these molecules changed in their PSD concentration (Fig. 2B). The antibody used against PSD-95 detected a high molecular weight band (Fig. $2 A$ ) that disappeared in $P S D-93^{-1-}$ (Fig. $3 A$ ) indicating that the antibody also recognized PSD-93. Using this antibody we have seen that PSD-93 is also increased in the lipid fraction of $P S D-95^{-1-}$ animals while unchanged in the PSD.

We also analyzed the concentration of NMDAR subunits and PSD-93 in the detergent-soluble extract. The concentration of NR1, NR2A and PSD-93 decreased in this fraction, correlating

B
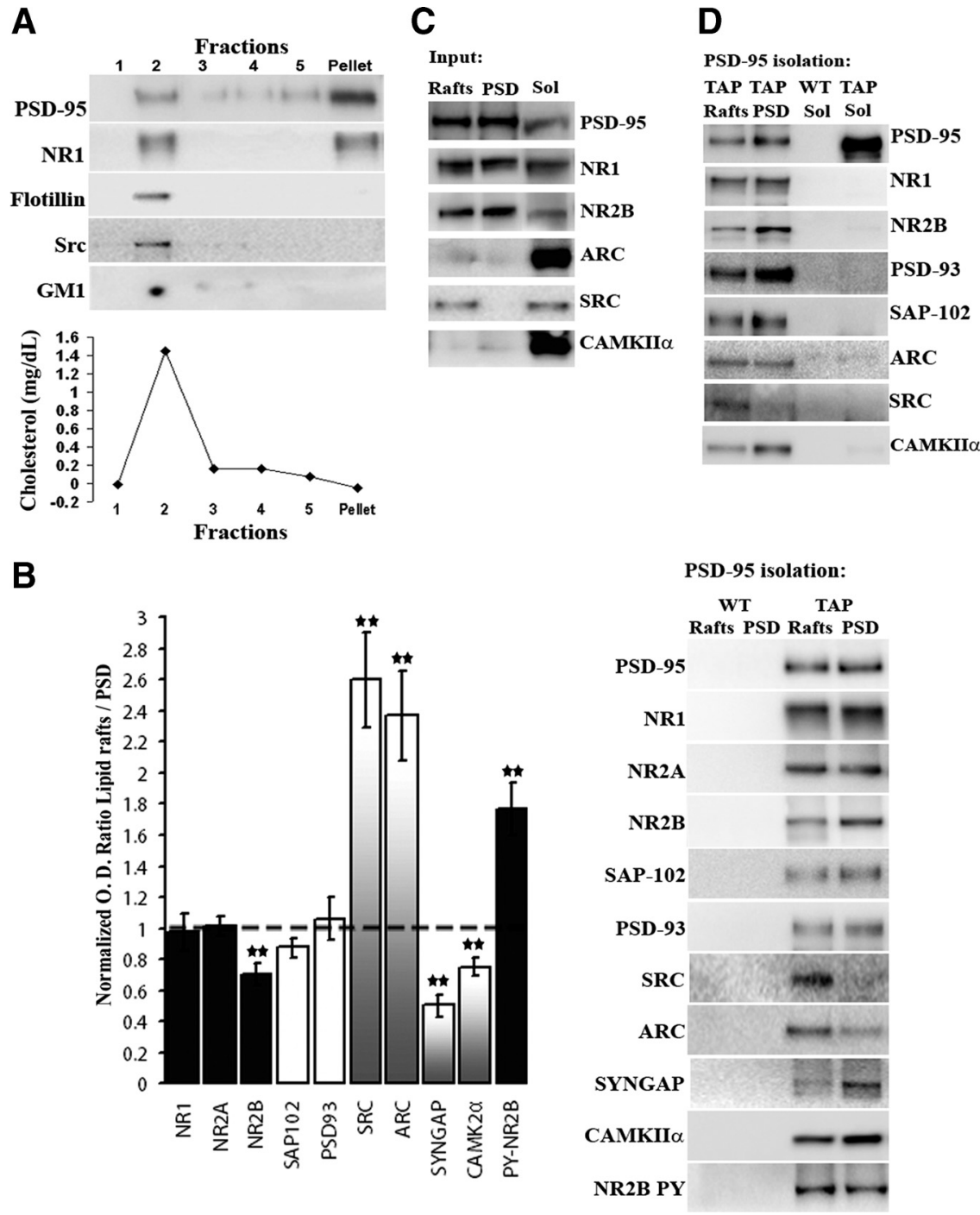

Figure 1. Composition of the PSD-95-NMDAR complex in lipid rafts and PSD fractions. $\boldsymbol{A}$, Mouse cortices were extracted in $1 \%$ Triton X-100 and separated on a density gradient. Five fractions (from top to bottom of the gradient) were obtained from each gradient and equal volumes of these fractions, were immunoblotted for the indicated proteins. Fractions were also assayed for the sphingolipid GM1 (dot-blot assay using cholera toxin) and cholesterol (colorimetric assay). $\boldsymbol{B}$, Lipid rafts and PSD-enriched fractions indicated proteins. The densitometry readings of the blots were normalized against the optical density of PSD-95, except the (mean \pm SEM) expressed as the ratio lipid rafts/PSD for at least 4 independent experiments. C, Detergent-soluble extract (Sol) and lipid rafts (Rafts) and PSD fractions (PSD) were immunoblotted against the indicated proteins. Protein amounts loaded: Raft, 3.2 $\mu \mathrm{g}$; PSD, $3.2 \mu \mathrm{g}$; Sol, $192 \mu \mathrm{g}$. D, TAP PSD-95 complexes were isolated from lipid rafts (Rafts), PSD fractions (PSD) and detergentsoluble extract (Sol) from wild-type (WT) and PSD-95 ${ }^{\text {TAP }}$ (TAP) mice with anti-Flag antibody and subsequently released by TEV protease cleavage. The eluted complexes were immunoblotted against indicated proteins. ${ }^{* *} p<0.01,{ }^{*} p<0.05$.

with their increase in lipid rafts (Fig. 2D). In addition, the expression of NMDAR subunits in crude homogenate did not differ between PSD-95 ${ }^{-1-}$ and wt mice (Fig. $2 C$ ). These data indicate that PSD-95 is required to modulate the levels of NR1, NR2A in rafts and soluble fractions.

Since the amino acid sequence of PSD-95 and PSD-93 reveals $71 \%$ identity, and the same domain organization including the palmitoylation motif (El-Husseini et al., 2000; Dakoji et al., 2003; Fitzjohn et al., 2006) the increase of NMDAR associated to lipid rafts in PSD-95 ${ }^{-1-}$ mice may be due to the increase of PSD-93 in this fraction. Therefore, we examined the distribution of the NMDA receptor subunits and other proteins in $P S D-93^{-1-}$ 
A

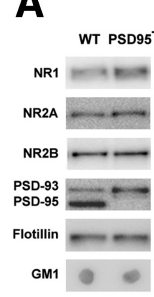

C

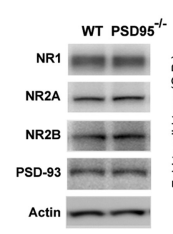

LIPID RAFT FRACTION

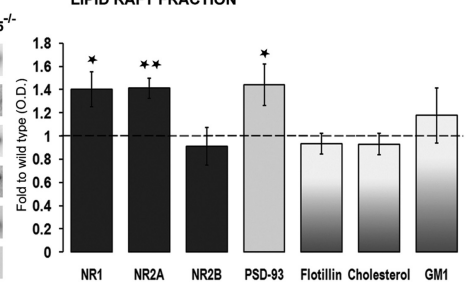

CRUDE HOMOGENIZED

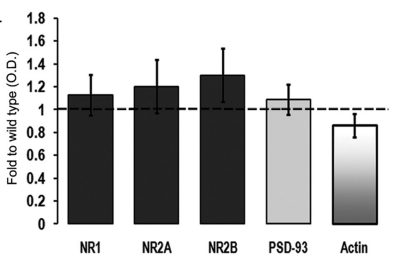

B

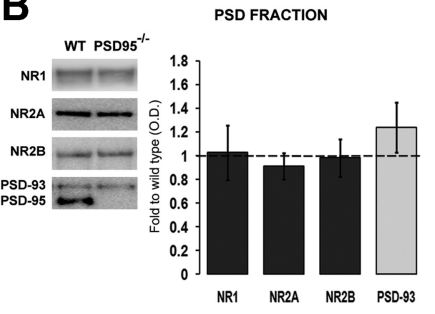

D

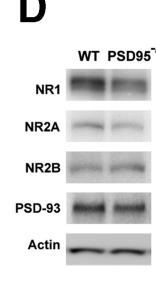

Figure 2. Analysis of PSD-95 $-1-$ knock-out mice. Cortices of wild-type and PSD-95 $-1-$ litter-matched mice were dissected and the lipid rafts were isolated by density gradient centrifugation. $\boldsymbol{A}$, Equal amounts of proteins from Lipid raft (fraction 2) were analyzed by Western blot for indicated proteins; equal volumes of the fractions were analyzed for GM1 amount (dot blot) (left panel) and cholesterol (spectrophotometer determination). $\boldsymbol{B}$, Equal amounts of proteins from the PSDs (pellets) were analyzed by Western blot for the indicated proteins. C, Total proteins in crude homogenate were analyzed by Western blot. D, Concentrations of the indicated proteins in the detergent-soluble extract were analyzed by Western blot. Graphics show densitometry analysis of blots (mean \pm SEM) expressed as the ratio of immunoreactivity (PSD-95 ${ }^{-1-}$ mice over litter-matched wild-type) for five independent experiments, except $(\boldsymbol{D})$ detergent-soluble extract (4 litter matched pairs of animals), ${ }^{* *} p<0.01,{ }^{*} p<0.05$.
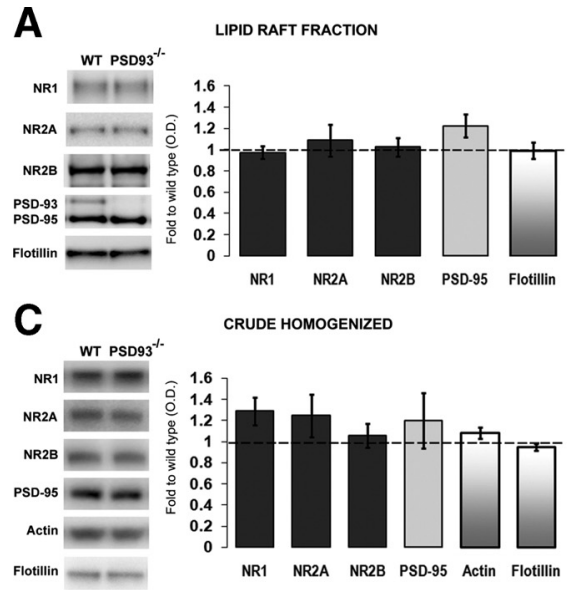
CRUDE HOMOGENIZED

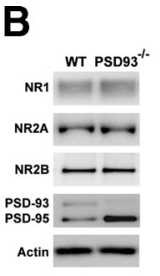

D

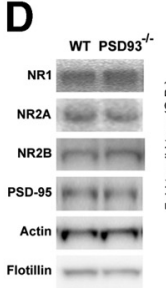

PSD FRACTION

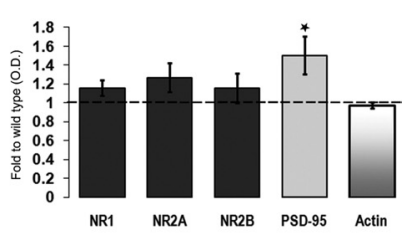

DETERGENT-SOLUBLE EXTRACT

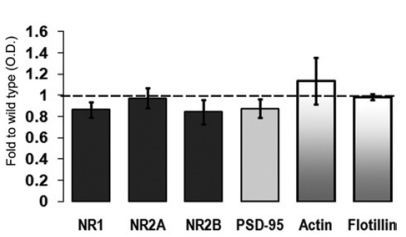

Figure 3. $\quad A-D$, Analysis of PSD- $93^{-1-}$ knock-out mice. Cortices of wild-type (WT) and PSD-95 ${ }^{-1-}$ litter-matched mice were dissected and the lipid rafts isolated by density gradient. Equal amounts of proteins of lipid raft $(\boldsymbol{A})$ and PSD $(\boldsymbol{B})$ were analyzed by Western blot for indicated proteins. $C$, Total proteins in crude homogenate were analyzed by Western blot. $\boldsymbol{D}$, Total proteins in the detergent-soluble extract were analyzed by Western blot. Graphics show densitometry analysis of blots (mean \pm SEM) expressed as the ratio of immunoreactivity (PSD-93 ${ }^{-1-}$ mice over litter-matched wild-types) for five independent experiments, except (D) detergent-soluble extract (4 litter matched pairs of animals), ${ }^{* *} p<0.01,{ }^{*} p<0.05$. (KO) PSD-95 ${ }^{-1-}$ knock-out mice; (WT) wild-type mice.

knock-out mice. The only observed change was an increase in PSD-95 in the PSD fraction (Fig. 3B). This comparison shows that MAGUKs play a role in organizing NMDA receptors in rafts, with PSD-95 playing a more important role than PSD-93.

\section{Association of NMDAR with}

\section{lipid rafts in mice with an NR2A C-terminal deletion}

Results from the MAGUK mutant mice suggest the physical interaction between NR2 subunits and MAGUKs regulates the localization of NMDA receptor to rafts. Since this interaction is mediated by the cytoplasmic tail of NR2 subunits, we examined the distribution of NR1, NR2B, and PSD-95 in lipid rafts, PSD and detergent-soluble fractions in mice lacking the cytoplasmic tail of NR2A protein $\left(\mathrm{NR} 2 \mathrm{~A}^{\Delta \mathrm{C} / \Delta \mathrm{C}}\right)$ (Sprengel et al., 1998) (Fig. 4). Interestingly, we found a $\sim 35 \%(p<0.01)$ reduction of NR1 in the crude homogenate, reflecting an overall reduction in this protein (Fig. 4C). This decrease in NR1 was greater in lipid rafts $(\sim 70 \%, p<0.01)$ (Fig. $4 A)$ than in PSD $(\sim 20 \%, p<0.05)$ (Fig. $4 B$ ), while it remained unchanged in the soluble fraction. (Fig. 4D). Using an antibody that recognizes the N-terminal domain of NR2A, we found in $\mathrm{NR} 2 \mathrm{~A}^{\Delta \mathrm{C} / \Delta \mathrm{C}}$ mice that the amount of NR2A was decreased $\sim 70 \%$ in both the lipid rafts and the PSD fraction $(p<$ 0.01 ), whereas it was increased $>3$ times in the soluble fraction. The total expression of the NR2A decreased $\sim 50 \%$. No changes were observed for NR2B in any of the fractions. We also observed that PSD-95 was reduced by $\sim 35 \%(p<0.01)$ in rafts (Fig. $4 A$ ). These data support the conclusion that the carboxyl intracellular domain of NR2A modulates the total level of NMDAR having its most significant effect in lipid rafts.

\section{NMDAR in lipid rafts from mice} lacking the PDZ binding motif of NR2B Since absence of the NR2A carboxyl intracellular domain decreased the amount of NMDAR in rafts we tested whether lack of the NR2B PDZ binding motif would have an effect on NMDAR raft partitioning using $N R 2 B^{\Delta V / \Delta V}$ mice. During the course of routine control experiments we measured total protein, GM1, cholesterol and flotillin-1 in the different fractions (Fig. 1A) and we unexpectedly found a change in raft composition in the $N R 2 B \quad \Delta V / \Delta V$ mice. The concentration of total protein and raft markers were increased by $\sim 35 \%$ in the lipid raft fraction from $N R 2 B^{\Delta V / \Delta V}$ animals compared with controls. No changes were observed in total protein in the PSD fraction (Fig. 5A). To confirm that this increase was specific to rafts, we measured GM1, flotillin-1 and cholesterol in the detergentsoluble and insoluble extracts: the increases were only present in the insoluble extract (lipid raft plus PSD) (Fig. 5A). These increases in raft markers are consistent with an increase in the synthesis or stabilization of the lipid rafts components (Fig. 5D).

This increase of rafts in $N R 2 B^{\Delta V / \Delta V}$ mice was also associated with changes in the proportions of NMDAR subunits and MAGUK proteins. The relative amounts of NR1 and NR2B in rafts was decreased by $\sim 40 \%(p<0.01)$ whereas NR2A, PSD-95 and actin were unchanged in $N R 2 B^{\Delta V / \Delta V}$ mice (Fig. $5 B$ ). To clarify the net effect of the changes in raft amounts and the concentrations of the particular proteins we examined the total amounts of the proteins (per volume) and found NR1 and NR2B in raft fraction in $N R 2 B^{\Delta V / \Delta V}$ mice was similar to levels in wild-type extracts, while PSD-95 was increased (data not shown). 
Unlike the rafts, the total amount of PSD proteins did not change in $N R 2 B^{\Delta V / \Delta V}$ mice. Nevertheless, the mutation had a clear effect on NMDA receptor expression, since NR1 and NR2B concentration decreased by $\sim 20 \%$ and $\sim 25 \%$ respectively $(p<0.05)$. Conversely, the amount of NR2A was increased by $\sim 45 \%$ in the PSD. This suggests a compensatory increase in NR2A occurred in the PSD. We also examined the detergent-soluble extract, where decreased levels of PSD-95 and NR2A were observed and NR1 levels did not change (Fig. 5E). Moreover it should be noted that PSD-95 and actin was unchanged in PSDs and total homogenate indicating that the loss of the single residue from NR2B did not influence these scaffold and structural proteins in these fractions. Together these data indicate that the terminal valine residue of NR2B is required for the normal expression of synaptic signaling proteins in different synaptic compartments.

\section{Discussion}

\section{Lipid rafts at excitatory synapses}

Using genetically modified mice carrying a tandem affinity purification tag inserted into PSD-95 we demonstrate that neurotransmitter receptor signaling complexes have different composition and phosphorylation in PSD and rafts. While rafts have been described in a wide range of cells, we have focused on glutamatergic synapses where the complexes formed with PSD-95 are highly enriched in the postsynaptic terminal allowing us to separate excitatory synaptic rafts from those in other cells and compartments. Among the known important raft proteins at excitatory synapses are glutamate receptors: AMPA (Sprengel et al., 1998; Suzuki et al., 2001), NMDA (Besshoh et al., 2005; Delint-Ramírez et al., 2008; Wheeler et al., 2009) and metabotropic receptors (mGLUR1/5) (Francesconi et al., 2009); scaffold proteins such as PSD-95 (Wong and Schlichter, 2004; Suzuki et al., 2008) and GRIP (glutamate receptor-interacting protein) (Brückner et al., 1999; Hering et al., 2003). Moreover, a number of raft markers have been localized to the postsynaptic terminal: flotillin-1 (Collins et al., 2006) that was also reported to interact with NMDA receptors (Swanwick et al., 2009); caveolin-1 found by electron microscopy (Petralia et al., 2003) and interacts with mGLUR receptors (Francesconi et al., 2009) and NMDARs were colocalized by confocal microscopy with the raft marker ganglioside GM1 (Frank et al., 2004). These data are all consistent with a model in which lipid rafts constitute an integral structural component of the postsynaptic apparatus and supports the suggestion that they are involved in the regulation of postsynaptic structure and function.

The ultrastructural organization of rafts within the postsynaptic terminal and their physical relationship with the PSD remains unclear. Evidence that the postsynaptic membrane has lipid-raft regions that limit the diffusion of molecules was observed using new microscopy methods and cholesterol depletion, which increased the mobility in the synaptic membrane of slowly diffusing molecules (Renner et al., 2009). This is also consistent with data showing that lipid rafts have a different viscosity
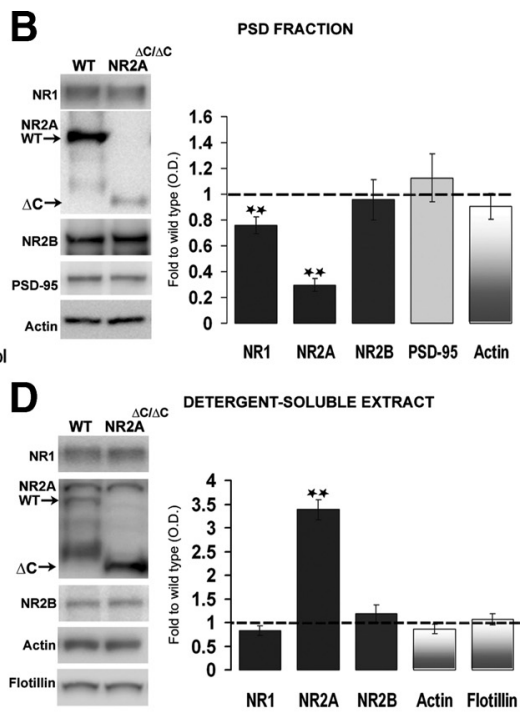

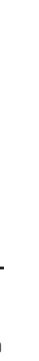

D

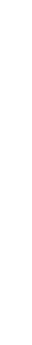

Figure 4. Analysis of mice carrying a C-terminal truncation of NR2A subunits (NR2A $A^{\Delta C / \Delta C}$ ). Cortices of wild-type and $N R 2 A^{\Delta C / \Delta C}$ 作 the ratio of immunoreactivity (NR2A $A^{\Delta C / \Delta C}$ mice over wild types) for six independent pairs of litter-matched mice, except (D) RUDE HOMOGENIZED

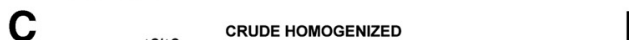



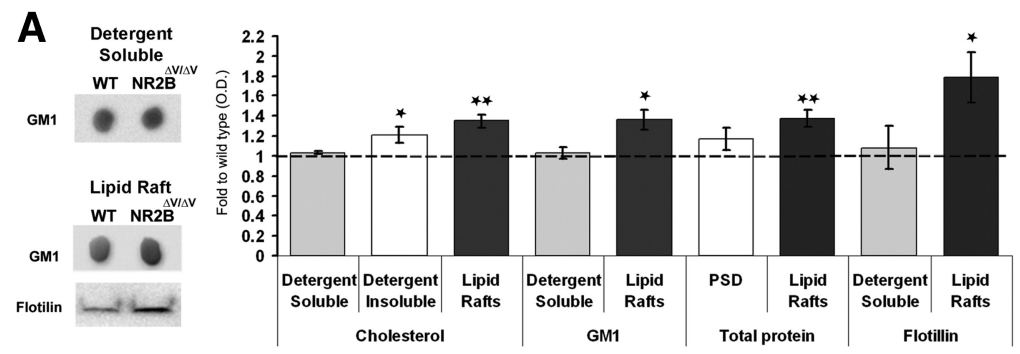

B

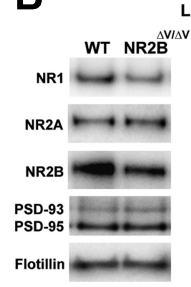

LIPID RAFT FRACTION
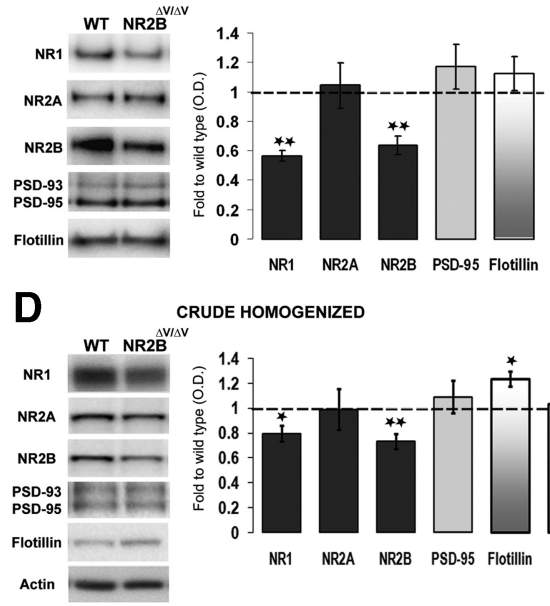

CRUDE HOMOGENIZED

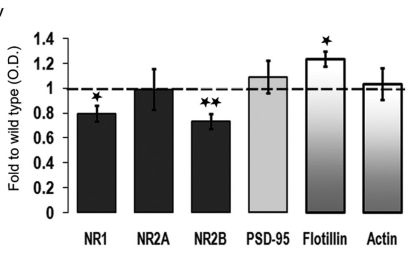

C
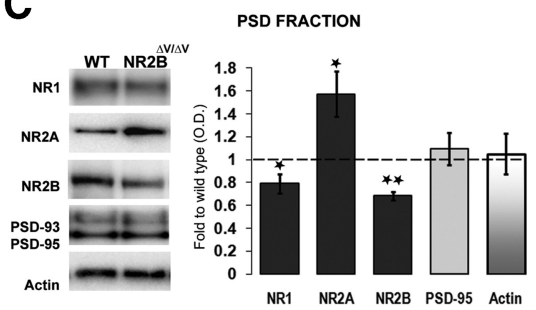

E

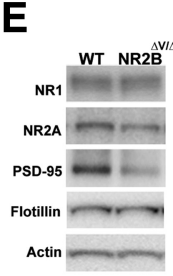

DETERGENT-SOLUBLE EXTRACT VIISV

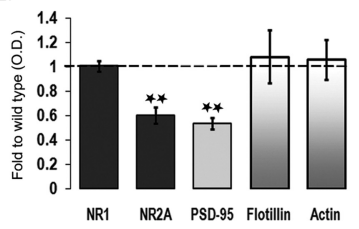

Figure 5. Analysis of carrying a punctual deletion of the Valine 1482 of NR2B subunits (NR2B ${ }^{\Delta V / \Delta V}$ ) Cortices of wild-type and $N R 2 B^{\Delta V / \Delta V}$ litter-matched mice were dissected and lipid rafts were isolated by density gradient. $A$, Equal volumes of soluble and insoluble Triton X-100 extract (resuspended in lyses buffer), and lipid rafts and PSD fractions were analyzed for GM1 (dot blot), cholesterol (colorimetric assay), total protein (Bradford), or Flotillin-1 (Western blot). B, C, Equal amounts of proteins from lipid rafts and PSD fractions were analyzed by Western blot for the indicated proteins. $\boldsymbol{D}$, Expression of proteins in crude homogenized tissue was analyzed by Western blot. $\boldsymbol{E}$, Concentration of the indicated proteins in the detergent-soluble extracted was analyzed by Western blot. Graphics show spectrophotometric reading and densitometry analysis of blots (mean \pm SEM) expressed as the ratio of immunoreactivity (KO mice over wild types) for six independent experiments, except (D) detergent-soluble extract (4 litter matched pairs of animals), ${ }^{* *} p<0.01,{ }^{*} p<0.05$.

was almost threefold higher in the raft PSD-95 complexes. Conversely, the amount of SynGAP and CaMKII $\alpha$ in PSD-95 complexes was $\approx 25 \%$ and $50 \%$ less in rafts than PSDs.

All the differentially associated proteins are known to be important in synaptic plasticity (Malenka et al., 1989; O'Dell et al., 1991; Grant et al., 1992; Komiyama et al., 2002). Moreover, the pattern of differences in particular proteins between rafts and PSDs was clearly relevant to known functional interactions of these proteins. For example, CaMKII $\alpha$ and SynGAP, which were reduced in rafts, form part of a signaling pathway where $\mathrm{Ca}^{2+}$ entering via the NMDAR dissociates CaMKII from the complex, which drives the dephosphorylation of SynGAP inhibiting its GTPase activity (Krapivinsky et al., 2004). Src was enriched in rafts as was the enhanced tyrosine phosphorylation of NR2B, which is a known Src phosphorylation site (Besshoh et al., 2005) and important for synaptic physiology and behavior (Rosenblum et al., 1997; Ali and Salter, 2001; Zinebi et al., 2003; Barki-Harrington et al., 2009). This suggests the NMDAR-PSD-95 complexes in rafts support the Src-NR2B pathway and the complexes in PSDs support a CaMKII $\alpha$ SynGAP pathway. Thus, increase in the association of the NMDAR with lipid rafts could promote the SRC signaling pathway after NMDAR activation, while decrease of the NMDAR affinity for rafts could promote the CaMKII-SynGAP pathway activation.

CaMKII is known to be associated with lipid rafts and ionomycin stimulation, which increases intracellular calcium, pro-

motes CaMKII clustering with lipid rafts (Du et al., 2006; Suzuki et al., 2008). The CaMKII clusters stabilized (became resistant to treatment with methyl- $\beta$ cyclodextrin) the association of PSD-95 with lipid rafts. The ionomycin stimulation did not recruit PSD-95 to rafts suggesting that different proteins in the raft complexes can be differentially regulated in their recruitment to raft complexes. Both CamKII and PSD-95 interact with NMDA receptor NR2 subunits C-terminal domains (Parkin et al., 1990), which we found to be important in organization of raft proteins.

Similar to Src, we found Arc/Arg3.1 was mainly coupled to the NMDARPSD-95 complexes in rafts. Arc/Arg3.1 is an immediate-early gene whose mRNA is rapidly transcribed and targeted to dendrites of neurons, where it has been implicated in AMPA receptor endocytosis (Guzowski, 2002; Chowdhury et al., 2006; Plath et al., 2006; Shepherd et al., 2006). The enrichment of Arc/Arg3.1 in raft PSD-95 complexes suggests that Arc/ Arg3.1 targeting to NMDA receptor complexes may preferentially localize to the PSD-95 complexes within rafts. Studies showing changes in NMDA receptor and PSD-95 in rafts following learning and plasticity (Besshoh et al., 2005; DelintRamírez et al., 2008) suggest these behaviors result in dynamic changes in the composition of the complexes.

Further evidence of differential composition of PSD-95 complexes in other cellular compartments was observed when examining the proteins associated with TAP tagged PSD-95 isolated from the detergent-soluble extract. There was a marked absence of the PSD-95 associated proteins, compared with rafts and PSDs, consistent with this complex being of extrasynaptic origin and perhaps representing PSD-95 in transit to the synapse where it assembles with its signaling partners.

The association of the proteins with lipid rafts is a very dynamic process (Pike, 2006) and future studies using fluorescenttagged synaptic proteins may allow the trafficking of proteins between complexes and compartments to be studied. Very recently, advances in experimental techniques have allowed for the first time, noninvasive in vivo imaging of single diffusing lipid molecules and proteins with unprecedented spatial resolution (Kenworthy, 2007; de Almeida et al., 2009; Loura et al., 2009, 2010). These techniques show that lipid rafts are nanoscale $(\approx 20 \mathrm{~nm}$ areas) assemblies, highly dynamic, fluctuating on a subsecond timescale (preexisting raft domains). These nanodomains can be stabilized by proteins that coalesce, forming platforms that function in membrane signaling and trafficking. When clustered, lipid raft components are thought to be laterally stabilized according to their underlying affinity for preexisting raft domains (Lingwood and Simons, 2007; Kaiser et al., 2009). Our results suggest that in the synaptic membrane, the affinity of some proteins for lipid rafts allow their interaction with other proteins with affinity for this 
domain, which determines the formation of different protein complexes.

\section{Roles for NR2 cytoplasmic domains and MAGUK proteins in raft complexes}

Synaptic NMDAR subunit numbers and composition are dynamically remodeled during development and in response to neuronal activity and sensory experience. Several studies show this remodeling occurs by subunit insertion into the synaptic membrane, endocytosis or lateral mobility between the synaptic and extrasynaptic membrane (Zukin and Bennett, 1995; Wenthold et al., 2003). Less is known about the sorting of NMDA receptors and their scaffold and signaling proteins into lipid rafts and non-raft membrane. In addition to finding evidence of differential distribution of these proteins, we also found that MAGUK proteins and NR2 cytoplasmic interaction domains were essential for regulating this distribution in vivo. Lack of PSD-95 increased the NR2A subunit in rafts and decreased it in the detergent-soluble extract without any significant effect on NR2B. It should be noted that PSD-93 was also increased in the rafts of PSD-95 ${ }^{-1-}$ mutant mice suggesting PSD-95 normally restrains NR2A-PSD-93 complexes from entering into rafts. In PSD-93 mutant mice, there was no detectable redistribution of NR2A, NR2B or PSD-95 suggesting that PSD-95 is a more important regulator of raft organization, possibly because PSD-95 is expressed about eight times as much as PSD-93 isoforms (Noritake et al., 2009). Additionally, our results suggest the MAGUK family plays a more important role on NR2A rather than NR2B since the knock-out of PSD-95 affected the association of NR2A but not $\mathrm{NR} 2 \mathrm{~B}$, and the deletion of the NR2A C-terminal tail decreased the association of NMDAR with lipid rafts by a greater amount than the mutation of the NR2B PDZ binding domain.

Direct evidence that NR2 cytoplasmic domains are involved in receptor and MAGUK distribution was found using mice lacking the cytoplasmic tail of the NR2A subunit. In these animals NR1 was reduced by $70 \%$ in rafts and $30 \%$ in PSDs. This did not affect synaptic NMDA receptor currents in CA3-CA1 synapses in these mutants (T.J. O'Dell personal communication). The simplest explanation is that NR2 C-terminal tail interactions with MAGUK proteins are involved in the NMDAR distribution, since mice carrying the point mutation in the PDZ binding domain of $\mathrm{NR} 2 \mathrm{~B}\left(N R 2 B^{\Delta V / \Delta V}\right)$ showed a reduction in the amount of NR2B in rafts. However we noticed that in the NR2A $A^{\Delta C / \Delta C}$ the amount of PSD-95 in rafts was also reduced. A potential mechanism that explains an NMDAR-dependent mechanism for raft recruitment of PSD-95 is that signal transduction from NMDAR drives palmitoylation of PSD-95 (Noritake et al., 2009) and this palmitoylation is sufficient to target it to rafts (Shenoy-Scaria et al., 1994). It is possible that there is a cooperative role between palmitoylation regulated trafficking and protein-protein associations between NR2 subunits and MAGUKs. Further evidence for this concept is seen in data showing CaMKII regulates the recruitment of proteins to lipid rafts (Suzuki et al., 2008). Recently it was reported that the cytoplasmic tail of NR2A and NR2B have two distinct clusters of palmitoylation (Hayashi et al., 2009). The palmitoylation within the first cluster is on a membrane proximal region and involved in the association of the NMDAR-PSD-95 complex with lipid rafts and allows tyrosine phosphorylation of the NR2B subunit (pY 1472 and 1252) by Src family protein tyrosine kinases. This is consistent with our observation of this phosphorylation occurring mainly in rafts.

A surprising result from our study was that the absence of the terminal valine from the NR2B subunit changed the amount and composition of rafts. There was an $\sim 30 \%$ increase in lipid rafts markers (GM1, cholesterol, and flotillin-1) and total protein. This increase of lipid raft markers was specifically in rafts since we did not detect changes in the detergent-soluble fraction. At the same time, this mutation decreased the concentration of NR1/ NR2B in rafts and PSD by $\sim 30 \%$, which is in agreement with unpublished data showing a $30 \%$ reduction in the synaptic NMDA receptor currents (T.J. O'Dell, personal communication). The increase of lipid rafts could be a regulatory response mechanism to recuperate the amount of NMDAR and recover the glutamatergic signaling. This regulatory response may involve changes in synthesis of rafts and a candidate mechanism may involve the PI3K-AKT-SREBP pathway, known to regulate synthesis of cholesterol and fatty acids pathways (Porstmann et al., 2005; Shacka et al., 2006; Boonsong et al., 2007; Fuhrman et al., 2007; Smith et al., 2008) and also coupled to NMDA receptor and PSD-95 function (Opazo et al., 2003; Sánchez-Pérez and Felipo, 2006; Sánchez-Pérez et al., 2006; Yoshii and ConstantinePaton, 2007; Abbott et al., 2008).

Our study shows for the first time that signaling complexes between NMDA receptor and MAGUK proteins are differentially organized in rafts and other fractions and shows important roles for the interactions between these proteins. This report also illustrates how in vivo studies using mice carrying genetically modified TAP tagged synaptic proteins and mutations can be combined to identify novel synaptic signaling mechanisms.

\section{References}

Abbott JJ, Howlett DR, Francis PT, Williams RJ (2008) Abeta(1-42) modulation of Akt phosphorylation via alpha7 nAChR and NMDA receptors. Neurobiol Aging 29:992-1001.

Ali DW, Salter MW (2001) NMDA receptor regulation by Src kinase signalling in excitatory synaptic transmission and plasticity. Curr Opin Neurobiol 11:336-342.

Barki-Harrington L, Elkobi A, Tzabary T, Rosenblum K (2009) Tyrosine phosphorylation of the $2 \mathrm{~B}$ subunit of the NMDA receptor is necessary for taste memory formation. J Neurosci 29:9219-9226.

Becher A, White JH, McIlhinney RA (2001) The gamma-aminobutyric acid receptor $B$, but not the metabotropic glutamate receptor type-1, associates with lipid rafts in the rat cerebellum. J Neurochem 79:787-795.

Besshoh S, Bawa D, Teves L, Wallace MC, Gurd JW (2005) Increased phosphorylation and redistribution of NMDA receptors between synaptic lipid rafts and post-synaptic densities following transient global ischemia in the rat brain. J Neurochem 93:186-194.

Boonsong T, Norton L, Chokkalingam K, Jewell K, Macdonald I, Bennett A, Tsintzas K (2007) Effect of exercise and insulin on SREBP-1c expression in human skeletal muscle: potential roles for the ERK1/2 and Akt signalling pathways. Biochem Soc Trans 35:1310-1311.

Brückner K, Pablo Labrador J, Scheiffele P, Herb A, Seeburg PH, Klein R (1999) EphrinB ligands recruit GRIP family PDZ adaptor proteins into raft membrane microdomains. Neuron 22:511-524.

Chowdhury S, Shepherd JD, Okuno H, Lyford G, Petralia RS, Plath N, Kuhl D, Huganir RL, Worley PF (2006) Arc/Arg3.1 interacts with the endocytic machinery to regulate AMPA receptor trafficking. Neuron 52: 445-459.

Coba MP, Pocklington AJ, Collins MO, Kopanitsa MV, Uren RT, Swamy S, Croning MD, Choudhary JS, Grant SG (2009) Neurotransmitters drive combinatorial multistate postsynaptic density networks. Sci Signal 2:ra19.

Collins MO, Yu L, Coba MP, Husi H, Campuzano I, Blackstock WP, Choudhary JS, Grant SG (2005) Proteomic analysis of in vivo phosphorylated synaptic proteins. J Biol Chem 280:5972-5982.

Collins MO, Husi H, Yu L, Brandon JM, Anderson CN, Blackstock WP, Choudhary JS, Grant SG (2006) Molecular characterization and comparison of the components and multiprotein complexes in the postsynaptic proteome. J Neurochem 97 [Suppl 1]:S16-S23.

Dakoji S, Tomita S, Karimzadegan S, Nicoll RA, Bredt DS (2003) Interaction of transmembrane AMPA receptor regulatory proteins with multiple membrane associated guanylate kinases. Neuropharmacology 45: $849-856$ 
de Almeida RF, Loura LM, Prieto M (2009) Membrane lipid domains and rafts: current applications of fluorescence lifetime spectroscopy and imaging. Chem Phys Lipids 157:61-77.

Delint-Ramírez I, Salcedo-Tello P, Bermudez-Rattoni F (2008) Spatial memory formation induces recruitment of NMDA receptor and PSD-95 to synaptic lipid rafts. J Neurochem 106:1658-1668.

Du F, Saitoh F, Tian QB, Miyazawa S, Endo S, Suzuki T (2006) Mechanisms for association of $\mathrm{Ca} 2+/$ calmodulin-dependent protein kinase II with lipid rafts. Biochem Biophys Res Commun 347:814-820.

El-Husseini AE, Topinka JR, Lehrer-Graiwer JE, Firestein BL, Craven SE, Aoki C, Bredt DS (2000) Ion channel clustering by membraneassociated guanylate kinases. Differential regulation by N-terminal lipid and metal binding motifs. J Biol Chem 275:23904-23910.

Emes RD, Pocklington AJ, Anderson CN, Bayes A, Collins MO, Vickers CA, Croning MD, Malik BR, Choudhary JS, Armstrong JD, Grant SG (2008) Evolutionary expansion and anatomical specialization of synapse proteome complexity. Nat Neurosci 11:799-806.

Fernández E, Collins MO, Uren RT, Kopanitsa MV, Komiyama NH, Croning MD, Zografos L, Armstrong JD, Choudhary JS, Grant SG (2009) Targeted tandem affinity purification of PSD-95 recovers core postsynaptic complexes and schizophrenia susceptibility proteins. Mol Syst Biol 5:269.

Fitzjohn SM, Doherty AJ, Collingridge GL (2006) Promiscuous interactions between AMPA-Rs and MAGUKs. Neuron 52:222-224.

Francesconi A, Kumari R, Zukin RS (2009) Regulation of group I metabotropic glutamate receptor trafficking and signaling by the caveolar/lipid raft pathway. J Neurosci 29:3590-3602.

Frank C, Giammarioli AM, Pepponi R, Fiorentini C, Rufini S (2004) Cholesterol perturbing agents inhibit NMDA-dependent calcium influx in rat hippocampal primary culture. FEBS Lett 566:25-29.

Fuhrman B, Nitzan O, Karry R, Volkova N, Dumler I, Aviram M (2007) Urokinase plasminogen activator (uPA) stimulates cholesterol biosynthesis in macrophages through activation of SREBP-1 in a PI3-kinase and MEK-dependent manner. Atherosclerosis 195:e108-116.

Grant SG, O’Dell TJ, Karl KA, Stein PL, Soriano P, Kandel ER (1992) Impaired long-term potentiation, spatial learning, and hippocampal development in fyn mutant mice. Science 258:1903-1910.

Guirland C, Suzuki S, Kojima M, Lu B, Zheng JQ (2004) Lipid rafts mediate chemotropic guidance of nerve growth cones. Neuron 42:51-62.

Guzowski JF (2002) Insights into immediate-early gene function in hippocampal memory consolidation using antisense oligonucleotide and fluorescent imaging approaches. Hippocampus 12:86-104.

Hayashi T, Thomas GM, Huganir RL (2009) Dual palmitoylation of NR2 subunits regulates NMDA receptor trafficking. Neuron 64:213-226.

Hering H, Lin CC, Sheng M (2003) Lipid rafts in the maintenance of synapses, dendritic spines, and surface AMPA receptor stability. J Neurosci 23:3262-3271.

Husi H, Grant SG (2001) Isolation of 2000-kDa complexes of N-methyl-Daspartate receptor and postsynaptic density 95 from mouse brain. J Neurochem 77:281-291.

Husi H, Ward MA, Choudhary JS, Blackstock WP, Grant SG (2000) Proteomic analysis of NMDA receptor-adhesion protein signaling complexes. Nat Neurosci 3:661-669.

Kaiser HJ, Lingwood D, Levental I, Sampaio JL, Kalvodova L, Rajendran L, Simons K (2009) Order of lipid phases in model and plasma membranes. Proc Natl Acad Sci U S A 106:16645-16650.

Kenworthy AK (2007) Fluorescence recovery after photobleaching studies of lipid rafts. Methods Mol Biol 398:179-192.

Komiyama NH, Watabe AM, Carlisle HJ, Porter K, Charlesworth P, Monti J, Strathdee DJ, O'Carroll CM, Martin SJ, Morris RG, O’Dell TJ, Grant SG (2002) SynGAP regulates ERK/MAPK signaling, synaptic plasticity, and learning in the complex with postsynaptic density 95 and NMDA receptor. J Neurosci 22:9721-9732.

Kornau HC, Schenker LT, Kennedy MB, Seeburg PH (1995) Domain interaction between NMDA receptor subunits and the postsynaptic density protein PSD-95. Science 269:1737-1740.

Krapivinsky G, Medina I, Krapivinsky L, Gapon S, Clapham DE (2004) SynGAP-MUPP1-CaMKII synaptic complexes regulate p38 MAP kinase activity and NMDA receptor-dependent synaptic AMPA receptor potentiation. Neuron 43:563-574.

Lenne PF, Wawrezinieck L, Conchonaud F, Wurtz O, Boned A, Guo XJ, Rigneault H, He HT, Marguet D (2006) Dynamic molecular confine- ment in the plasma membrane by microdomains and the cytoskeleton meshwork. EMBO J 25:3245-3256.

Lingwood D, Simons K (2007) Detergent resistance as a tool in membrane research. Nat Protoc 2:2159-2165.

Loura LM, de Almeida RF, Silva LC, Prieto M (2009) FRET analysis of domain formation and properties in complex membrane systems. Biochim Biophys Acta 1788:209-224.

Loura LM, Fernandes F, Prieto M (2010) Membrane microheterogeneity: Förster resonance energy transfer characterization of lateral membrane domains. Eur Biophys J 39:589-607.

Ma L, Huang YZ, Pitcher GM, Valtschanoff JG, Ma YH, Feng LY, Lu B, Xiong WC, Salter MW, Weinberg RJ, Mei L (2003) Ligand-dependent recruitment of the ErbB4 signaling complex into neuronal lipid rafts. J Neurosci 23:3164-3175.

Malenka RC, Kauer JA, Perkel DJ, Mauk MD, Kelly PT, Nicoll RA, Waxham MN (1989) An essential role for postsynaptic calmodulin and protein kinase activity in long-term potentiation. Nature 340:554-557.

Marguet D, Lenne PF, Rigneault H, He HT (2006) Dynamics in the plasma membrane: how to combine fluidity and order. EMBO J 25:3446-3457.

Marta CB, Taylor CM, Coetzee T, Kim T, Winkler S, Bansal R, Pfeiffer SE (2003) Antibody cross-linking of myelin oligodendrocyte glycoprotein leads to its rapid repartitioning into detergent-insoluble fractions, and altered protein phosphorylation and cell morphology. J Neurosci 23:5461-5471.

McGee AW, Topinka JR, Hashimoto K, Petralia RS, Kakizawa S, Kauer FW, Aguilera-Moreno A, Wenthold RJ, Kano M, Bredt DS (2001) PSD-93 knock-out mice reveal that neuronal MAGUKs are not required for development or function of parallel fiber synapses in cerebellum. J Neurosci 21:3085-3091.

Melkonian KA, Ostermeyer AG, Chen JZ, Roth MG, Brown DA (1999) Role of lipid modifications in targeting proteins to detergent-resistant membrane rafts. Many raft proteins are acylated, while few are prenylated. J Biol Chem 274:3910-3917.

Noritake J, Fukata Y, Iwanaga T, Hosomi N, Tsutsumi R, Matsuda N, Tani H, Iwanari H, Mochizuki Y, Kodama T, Matsuura Y, Bredt DS, Hamakubo T, Fukata M (2009) Mobile DHHC palmitoylating enzyme mediates activity-sensitive synaptic targeting of PSD-95. J Cell Biol 186:147-160.

Núñez-Jaramillo L, Jimenez B, Ramirez-Munguía N, Delint-Ramírez I, LunaIllades C, Tapia R, Bermúdez-Rattoni F (2008) Taste novelty induces intracellular redistribution of NR2A and NR2B subunits of NMDA receptor in the insular cortex. Brain Res 1215:116-122.

O'Dell TJ, Kandel ER, Grant SG (1991) Long-term potentiation in the hippocampus is blocked by tyrosine kinase inhibitors. Nature 353:558-560.

Opazo P, Watabe AM, Grant SG, O’Dell TJ (2003) Phosphatidylinositol 3-kinase regulates the induction of long-term potentiation through extracellular signal-related kinase-independent mechanisms. J Neurosci 23:3679-3688.

Parkin AJ, Reid TK, Russo R (1990) On the differential nature of implicit and explicit memory. Mem Cognit 18:507-514.

Petralia RS, Wang YX, Wenthold RJ (2003) Internalization at glutamatergic synapses during development. Eur J Neurosci 18:3207-3217.

Pike LJ (2006) Rafts defined: a report on the Keystone Symposium on Lipid Rafts and Cell Function. J Lipid Res 47:1597-1598.

Plath N, Ohana O, Dammermann B, Errington ML, Schmitz D, Gross C, Mao X, Engelsberg A, Mahlke C, Welzl H, Kobalz U, Stawrakakis A, Fernandez E, Waltereit R, Bick-Sander A, Therstappen E, Cooke SF, Blanquet V, Wurst W, Salmen B, et al. (2006) Arc/Arg3.1 is essential for the consolidation of synaptic plasticity and memories. Neuron 52:437-444.

Porstmann T, Griffiths B, Chung YL, Delpuech O, Griffiths JR, Downward J, Schulze A (2005) PKB//Akt induces transcription of enzymes involved in cholesterol and fatty acid biosynthesis via activation of SREBP. Oncogene 24:6465-6481.

Renner M, Choquet D, Triller A (2009) Control of the postsynaptic membrane viscosity. J Neurosci 29:2926-2937.

Rosenblum K, Berman DE, Hazvi S, Lamprecht R, Dudai Y (1997) NMDA receptor and the tyrosine phosphorylation of its $2 \mathrm{~B}$ subunit in taste learning in the rat insular cortex. J Neurosci 17:5129-5135.

Sánchez-Pérez AM, Felipo V (2006) Chronic exposure to ammonia alters basal and NMDA-induced phosphorylation of NMDA receptor-subunit NR1. Neuroscience 140:1239-1244.

Sánchez-Pérez AM, Llansola M, Felipo V (2006) Modulation of NMDA receptors by AKT kinase. Neurochem Int 49:351-358. 
Shacka JJ, Sahawneh MA, Gonzalez JD, Ye YZ, D’Alessandro TL, Estévez AG (2006) Two distinct signaling pathways regulate peroxynitrite-induced apoptosis in PC12 cells. Cell Death Differ 13:1506-1514.

Sheng M (2001) The postsynaptic NMDA-receptor-PSD-95 signaling complex in excitatory synapses of the brain. J Cell Sci 114:1251.

Shenoy-Scaria AM, Dietzen DJ, Kwong J, Link DC, Lublin DM (1994) Cysteine3 of Src family protein tyrosine kinase determines palmitoylation and localization in caveolae. J Cell Biol 126:353-363.

Shepherd JD, Rumbaugh G, Wu J, Chowdhury S, Plath N, Kuhl D, Huganir RL, Worley PF (2006) Arc/Arg3.1 mediates homeostatic synaptic scaling of AMPA receptors. Neuron 52:475-484.

Simons M, Keller P, De Strooper B, Beyreuther K, Dotti CG, Simons K (1998) Cholesterol depletion inhibits the generation of beta-amyloid in hippocampal neurons. Proc Natl Acad Sci U S A 95:6460-6464.

Smith TM, Gilliland K, Clawson GA, Thiboutot D (2008) IGF-1 induces SREBP-1 expression and lipogenesis in SEB-1 sebocytes via activation of the phosphoinositide 3-kinase/Akt pathway. J Invest Dermatol 128:12861293.

Sprengel R, Suchanek B, Amico C, Brusa R, Burnashev N, Rozov A, Hvalby O, Jensen V, Paulsen O, Andersen P, Kim JJ, Thompson RF, Sun W, Webster LC, Grant SG, Eilers J, Konnerth A, Li J, McNamara JO, Seeburg PH (1998) Importance of the intracellular domain of NR2 subunits for NMDA receptor function in vivo. Cell 92:279-289.

Suzuki T, Ito J, Takagi H, Saitoh F, Nawa H, Shimizu H (2001) Biochemical evidence for localization of AMPA-type glutamate receptor subunits in the dendritic raft. Brain Res Mol Brain Res 89:20-28.

Suzuki T, Du F, Tian QB, Zhang J, Endo S (2008) Ca2+/calmodulindependent protein kinase IIalpha clusters are associated with stable lipid rafts and their formation traps PSD-95. J Neurochem 104:596-610.

Swanwick CC, Shapiro ME, Yi Z, Chang K, Wenthold RJ (2009) NMDA receptors interact with flotillin-1 and -2 , lipid raft-associated proteins. FEBS Lett 583:1226-1230.

Terpe K (2003) Overview of tag protein fusions: from molecular and biochemical fundamentals to commercial systems. Appl Microbiol Biotechnol 60:523-533.

Wenthold RJ, Prybylowski K, Standley S, Sans N, Petralia RS (2003) Trafficking of NMDA receptors. Annu Rev Pharmacol Toxicol 43:335-358.

Wheeler D, Knapp E, Bandaru VV, Wang Y, Knorr D, Poirier C, Mattson MP, Geiger JD, Haughey NJ (2009) Tumor necrosis factor-alpha-induced neutral sphingomyelinase- 2 modulates synaptic plasticity by controlling the membrane insertion of NMDA receptors. J Neurochem 109:12371249.

Wong W, Schlichter LC (2004) Differential recruitment of Kv1.4 and Kv4.2 to lipid rafts by PSD-95. J Biol Chem 279:444-452.

Yao WD, Gainetdinov RR, Arbuckle MI, Sotnikova TD, Cyr M, Beaulieu JM Torres GE, Grant SG, Caron MG (2004) Identification of PSD-95 as a regulator of dopamine-mediated synaptic and behavioral plasticity. Neuron 41:625-638.

Yoshii A, Constantine-Paton M (2007) BDNF induces transport of PSD-95 to dendrites through PI3K-AKT signaling after NMDA receptor activation. Nat Neurosci 10:702-711.

Zacharias DA, Violin JD, Newton AC, Tsien RY (2002) Partitioning of lipidmodified monomeric GFPs into membrane microdomains of live cells. Science 296:913-916.

Zinebi F, Xie J, Liu J, Russell RT, Gallagher JP, McKernan MG, ShinnickGallagher P (2003) NMDA currents and receptor protein are downregulated in the amygdala during maintenance of fear memory. J Neurosci 23:10283-10291.

Zukin RS, Bennett MV (1995) Alternatively spliced isoforms of the NMDARI receptor subunit. Trends Neurosci 18:306-313. 